\title{
MONITORING MASS CHANGES IN THE VOLTA RIVER BASIN USING GRACE SATELLITE GRAVITY AND TRMM PRECIPITATION
}

\author{
Mudanças em massa na bacia hidrográfica do Rio Volta empregando-se os satélites \\ GRACE e TRMM \\ ${ }^{1}$ VAGNER G. FERREIRA \\ ${ }^{2}$ ZHENG GONG ${ }^{*}$ \\ ${ }^{1,3}$ SAMUEL A. ANDAM-AKORFUL \\ ${ }^{1}$ School of Earth Sciences and Engineering \\ Hohai University, Nanjing, China \\ ${ }^{2}$ State Key Laboratory of Hydrology-Water Resources and Hydraulic Engineering \\ Hohai University, Nanjing, China \\ gongzheng@hhu.edu.cn \\ ${ }^{3}$ Department of Geomatic Engineering, College of Engineering \\ Kwame Nkrumah University of Science and Technology, Ghana
}

\begin{abstract}
GRACE satellite gravity data was used to estimate mass changes within the Volta River basin in West African for the period of January, 2005 to December, 2010. We also used the precipitation data from the Tropical Rainfall Measurement Mission (TRMM) to determine relative contributions source to the seasonal hydrological balance within the Volta River basin. We found out that the seasonal mass change tends to be detected by GRACE for periods from 1 month in the south to 4 months in the north of the basin after the rainfall events. The results suggested a significant gain in water storage in the basin at reference epoch 2007.5 and a dominant annual cycle for the period under consideration for both in the mass changes and rainfall time series. However, there was a low correlation between mass changes and rainfall implying that there must be other processes which cause mass changes without rainfall in the upstream of the Volta River basin.
\end{abstract}

Keywords: Equivalent Water Thickness; Mass Transport; Water Storage.

*Author to whom correspondence should be addressed

Bol. Ciênc. Geod., sec. Artigos, Curitiba, v. 18, nº 4, p.549-563, out-dez, 2012. 


\section{RESUMO}

Dados da missão Gravity Recovery and Climate Exchange (GRACE) são usados para estimar mudanças em massa na bacia hidrográfica do Rio Volta na Africa Ocidental entre o período de janeiro de 2005 a dezembro de 2010. Empregou-se também os dados de precipitação do satélite Tropical Rainfall Measurement Mission (TRMM) para determinar a fonte de contribuições em relação ao balanço hidrológico sazonal na bacia do Rio Volta. Os resultados mostram que a mudança de massa sazonal tende a ser detectada pelos satélites da missão GRACE a partir de 1 mês, no sul e de 4 meses no norte da bacia após a precipitação. Os resultados sugerem um ganho significativo no armazenamento d'água na bacia para a época de referência 2007,5 e um ciclo anual predominante para o período considerado para mudanças em massa e precipitação. No entanto, notou-se uma baixa correlação entre as alterações da massa e precipitação o que implica que deve haver outros processos que causam mudanças em massa sem ocorrer precipitação para o montante da bacia do Rio Volta.

Palavras-chave: Equivalente à Lâmina D’água; Transporte de Massa; Armazenamento D’água.

\section{INTRODUCTION}

Since 17 March 2002, the Gravity Recovery and Climate Experiment (GRACE) twin satellites have been used to monitor the gravity field of Earth in the space and time domains. Wahr et al. (1998) reported that the largest-amplitude and most varied time-dependent signals are related to water storage variability on land. Ramillien et al. (2008a) concluded that GRACE satellite gravimetry offers a very interesting alternative remote sensing technique to measure changes in total water storage over continental areas. This includes ice, snow, surface waters, soil moisture and groundwater. The measurements cannot distinguish between these stores, but can only recover the sum. However, the distribution of the locations of Earth's freshwater shows that the percentage of superficial water is very small $(\sim 1.3 \%)$ and we could consider that the main variations of the water storage are associated with groundwater storage $(\sim 30.1 \%)$.

Data of the GRACE satellite mission have been extensively applied to the study of the stored water changes. Recent publications suggest that water storage losses have occurred in central and south Asian (TANGDAMRONGSUB et al., 2011). The water storage changes from GRACE show decreasing trends in these regions. Lenk (2012) found that decreasing trends of terrestrial water storage changes observed by GRACE in the southern part of central Anatolia, Turkey, were largely explained by the decreasing trends of groundwater variations which were confirmed by in situ well groundwater level data. Crowley et al. (2006) estimated the water storage within the Congo Basin, Africa, and their results exhibit significant long-term trends yielding a total loss of $280 \mathrm{~km}^{3}$ of water over the fifty months of data. 
Over West Africa, only a few GRACE applications have been carried out with emphasis in the Niger River basin and Sahel region (e.g., GRIPPA et al., 2011 and HINDERER et al., 2011) and in basins in Sub-Saharan Africa (XIE et al., 2012). Other studies in a global scale also mentioned the Niger River basin, for example, Ramillien et al. (2008b) and Syed et al. (2008). Grippa et al. (2011) results revealed that GRACE data is able to reproduce the water storage inter-annual variability over the Sahel. Xie et al. (2012) have used seven years of GRACE data to calibrate a semi-distributed regional scale hydrological model Soil and Water Assessment Tool (SWAT). Their results showed that the simulated total water storage variations tend to have less agreement with the GRACE data in arid and equatorial humid regions. To the best of our knowledge there are no results in the literature regarding the mass changes in the Volta River basin, West African, using time-variable gravity fields from GRACE and precipitation data from the Tropical Rainfall Measurement Mission (TRMM).

Some 20 million people in the countries of Ghana, Burkina Faso, Mali, Benin, Togo and Ivory Coast (Côte d'Ivoire) make their homes within the river's basin shown in Figure 1. The river is highly depended upon by these countries for the purposes of irrigation, hydro-energy, industrial, and domestic usage. The most significant hydrological structure within the basin is the Akosombo Dam which holds back both the water of the White Volta, Black Volta and the Oti River for the generation of hydro-electric power. The dam forms the largest man-made lake in the world, the Volta Lake of a surface area of $8,500 \mathrm{~km}^{2}$ which lies entirely within Ghana.

The total of surface area of Volta Basin is about the $407,093 \mathrm{~km}^{2}$ and for that reason; the climate, soils and vegetation are largely variable in different regions. Rainfall is extremely low in the north and the south, increasing gradually to high values in the mid-section of the basin. Most streams within the basin are ephemeral; it is thus extremely difficult to find potable water in most parts of the basin during the dry season. Water storage changes are of particular importance in areas with arid or semi-arid climates within the Volta River basin. Information on the spatial and temporal behavior of terrestrial water storage is crucial for the management of local, regional and global water resources. In monitoring water storage traditionally, large amount of in-situ data from different points is required. GRACE however provides data over the entire basin without the need for ground data making it an ideal tool for this study (cf. DEUS et al., 2011 and MILZOW et al., 2011).

The aim of the present work is to compare the temporal variations of GRACEderived mass changes expressed as equivalent water thickness (EWT) and TRMM precipitation data over the Volta River basin. Hence the Stokes coefficients of monthly Earth's gravity solutions are applied; the gravity changes over Volta River basin are analyzed during 2005-2010. We also characterize the water storage variability in the Volta River basin to provide a guide for water management. The results showed an increase in the stored water. It is clearly depicted in the mass changes as well as the clearly seasonal and inter-annual changes. However, it seems 
that mass changes for the period were not caused by rainfall only. There must be some other processes involved which cause mass changes without rainfall.

Figure 1 - The Volta River and its Catchment Area (the red line is the main water divide of the hydrographic basin).

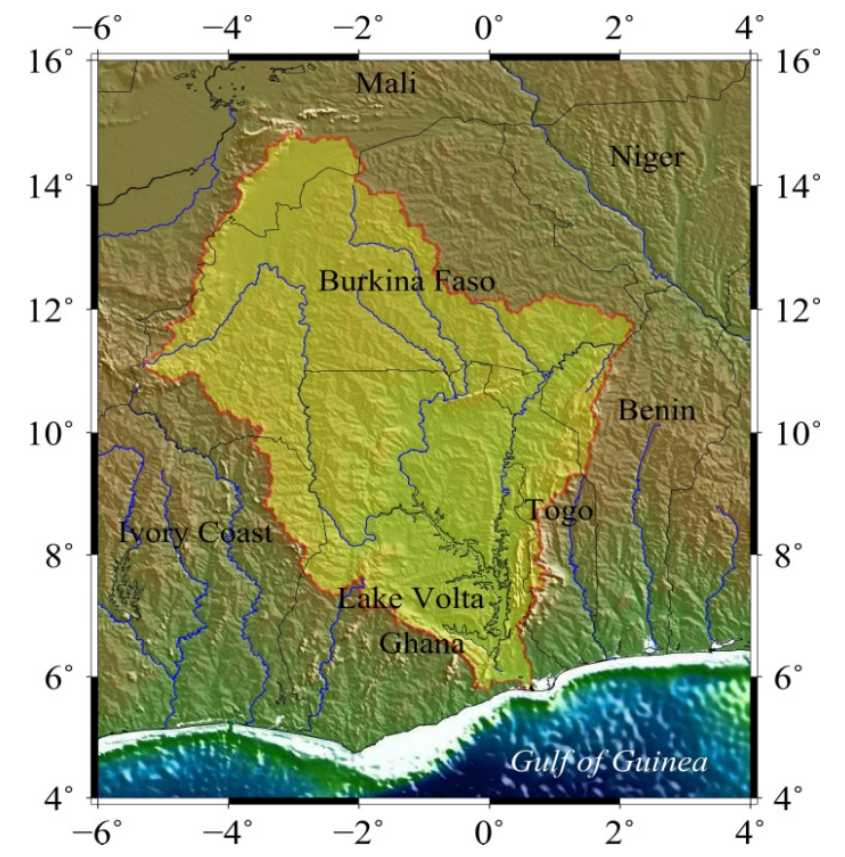

\section{DATA AND PROCESSING}

\subsection{Mass changes from GRACE}

Changes in the Stokes coefficients can be used to calculate changes in the geoid at a point with co-latitude $\vartheta$ and longitude $\lambda$. To convert variations of the geoid in equivalent water thickness (EWT) we used a filtering technique proposed by Wahr et al. (1998) which is based on the following assumptions:

- The mass variations in the water stored occur almost entirely within a thin layer of $1 \mathrm{~km}$ thick closer to the surface of the Earth. The density anomaly is concentrated within this thin layer.

- The deformation within the solid Earth due to mass at the surface can be represented in terms of load Love numbers.

- The density of the water is constant, so mass variations are associated to changes in the height of water layer. 
Under the above assumptions, the EWT can be expressed as (WAHR et al., 1998):

$$
h(t)=R \sum_{n=2}^{n_{\max }} \sum_{m=0}^{n} \bar{P}_{n, m}(\cos \vartheta)\left[\Delta \tilde{C}_{n, m}(t) \cos m \lambda+\Delta \tilde{S}_{n, m}(t) \sin m \lambda\right]
$$

at a given month $t$, where $\bar{P}_{n, m}$ is the normalized associated Legendre functions of degree $n$ and order $m, R$ is the mean radius of the Earth. $\Delta \tilde{C}_{n, m}$ and $\Delta \tilde{S}_{n, m}$ are the residual surface density coefficients obtained from the following relation (WAHR et al., 1998):

$$
\left(\begin{array}{c}
\Delta \tilde{C}_{n, m} \\
\Delta \tilde{S}_{n, m}
\end{array}\right)_{i}=\frac{\rho_{e}}{3 \rho_{w}} \frac{2 n+1}{1+k_{n}}\left(\begin{array}{c}
\Delta \bar{C}_{n, m} \\
\Delta \bar{S}_{n, m}
\end{array}\right)_{i},
$$

of the $i$-th monthly solution, where $\rho_{e}$ is the average density of the Earth, $\rho_{w}$ is the density of the water, and $k_{n}$ is the load Love number for degree $n$. Note that the equation (2) defines a simple filter that allows converting the variations of the geoid in EWT (usually expressed in $\mathrm{mm}$ ).

The residual Stokes's coefficients, $\Delta \bar{C}_{n, m}(t)$ and $\Delta \bar{S}_{n, m}(t)$ are defined by:

$$
\left(\begin{array}{l}
\Delta \bar{C}_{n, m} \\
\Delta \bar{S}_{n, m}
\end{array}\right)_{i}=\left(\begin{array}{l}
\bar{C}_{n, m} \\
\bar{S}_{n, m}
\end{array}\right)_{i}-\frac{1}{N} \sum_{j=1}^{N}\left(\begin{array}{l}
\bar{C}_{n, m} \\
\bar{S}_{n, m}
\end{array}\right)_{j},
$$

where the long-term value of $\bar{C}_{n, m}$ and $\bar{S}_{n, m}$, Stoke's coefficients, is removed. $N$ is the total number of monthly solutions. The reason for removing the mean field is that it is dominated by the static density distribution inside the solid Earth. Removing the static field means that all contribution from the means stored water is also removed. Thus, only the time-variable component of the water storage can be recovered.

\subsection{GRACE data set}

The GRACE observations are processed at the Center for Space Research (CSR) at the University of Texas, Jet Propulsion Laboratory (JPL), the GeoForschungsZentrum (GFZ), Centre National d'Études Spatiales (CNES) and Delft institute of Earth Observation, Space systems (DEOS) at Delft University of Technology and a few others institutions. However, each center follows different data processing methodologies, which may cause some differences in monthly sets of Stokes's coefficients (KLEES et al., 2008). The final results, known as Level 2 (L2) products, are the monthly geopotential solutions expressed in terms of spherical harmonic expansion, $c f$. Duan et al. (2009), which are widely used to 
study mass changes on the surface of the Earth. Each monthly Stokes's coefficients data set was referenced to the individual long term mean to derive residual timevariable quantities.

The data for this study include $N=72 \mathrm{GFZ}$ release 05 (GFZ-RL05) GRACE monthly solutions, $c f$. Dahle et al. (2012) for details, covering the time period from January 2005 to December 2010. These set of coefficients are complete up to a degree and order of 90 and they are available at: http://icgem.gfzpotsdam.de/ICGEM/shms/monthly/gfz-r105/. We limit the development in series up to degree and order 60, this limit $(n=60)$ fixes spatial resolution at approximately $334 \mathrm{~km}\left(\rho=\frac{\pi}{n} R\right)$. In contrast to RL04, the RL05's values are much closer to Satellite Laser Ranging (SLR) derived values, see Figure 2 for comparison. Because $C_{2,0}$ is affected by large tide-like aliases, it is necessary to replace $C_{2,0}$ with an independent estimate from SLR (CSR's approach for RL05). However, other option is to constrain $C_{2,0}$ to an a priori model during the gravity field solution process (GFZ's approach for RL05). Either approach achieves the same thing, which is to avoid the errors in $C_{2,0}$. For additional information we recommend Cheng and Tapley (2004), Cheng and Ries (2012), Bettadpur et al. (2012) and Dahle et al. (2012).

Figure 2 - Time series of $\bar{C}_{2,0}$ from SLR (RL04 and RL05) and GRACE (GFZRL05 and CSR-RL05). The respective mean values were subtracted for the four time series.

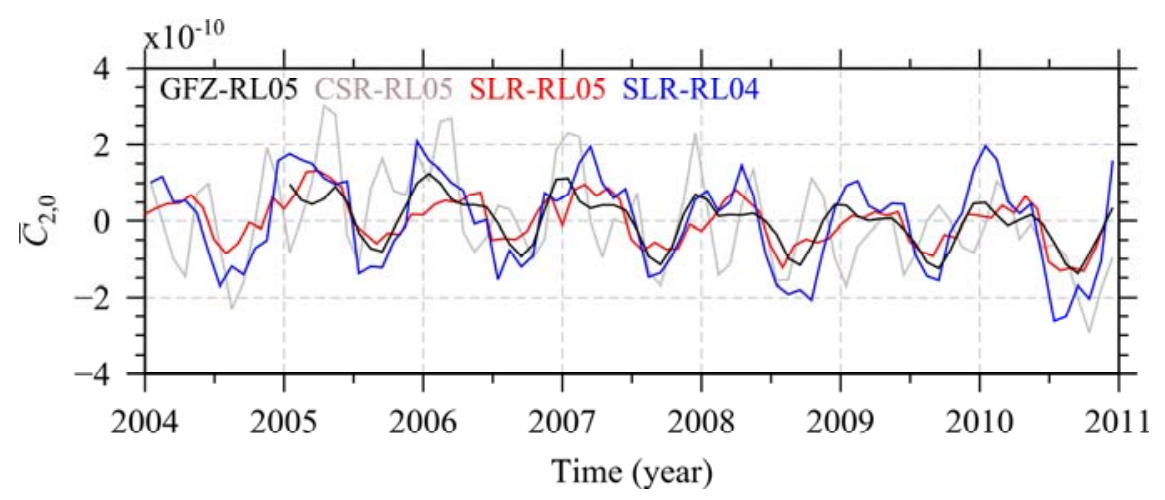

\subsection{Post-processing of GFZ-RL05's coefficients}

The maps of equivalent water thickness calculated with this methodology describe present linear features in north-south direction called as "stripes". The presence of these stripes indicates a high degree of spatial correlation in the GRACE errors in short wavelength components (high frequencies). Striping is the largest problem in GRACE solutions and according to Awange et al. (2009), there remains 
some conjecture as to the exact cause of the striping. However, in agreement with Swenson and Wahr (2006) and Schrama and Visser (2006) it is thought to be mostly due to weight being placed on the along-track K-band ranging (KBR) data coupled with inaccurate de-aliasing models and the mission configuration.

These systematic errors show a different tendency between odd and even degree coefficients for the same order. To obtain coherent results it is necessary to remove stripes using a post-processing method to reduce correlated error with a minimal impact in the real signal. Several methods have been used to remove stripes and noise of high frequency of GRACE data. These correlations can be reduced using either an empirical method based on a polynomial fit (SWENSON; WAHR, 2006) or an a priori synthetic model of the observation geometry (KUSCHE, 2007). In this study the polynomial fit scheme filter suggested by Chen et al. (2007) was applied to residual Stokes's coefficients. For residual Stokes's coefficients with orders 6 and above, a least square fit degree 4 polynomial was removed from even and odd degree coefficient pairs (CHEN et al., 2010). For example, for Stokes's coefficients of order 6 , we fit a degree 4 polynomial to the even degree pair (e.g., $\left.\Delta \bar{C}_{6,6}, \Delta \bar{C}_{8,6}, \ldots, \Delta \bar{C}_{60,6}\right)$ and remove the polynomial fit from the coefficients as shown in the Figure 3. The same process holds the odd degree pair (e.g., $\Delta \bar{C}_{7,6}$, $\left.\Delta \bar{C}_{9,6}, \ldots, \Delta \bar{C}_{59,6}\right)$. Chen et al. (2010) call this procedure the de-correlation filter, here after abbreviated as P4M6.

Figure 3 - Residual Stokes's coefficients $\Delta \bar{C}_{n, m}$ as function of degree $n$ and order $m=6$.

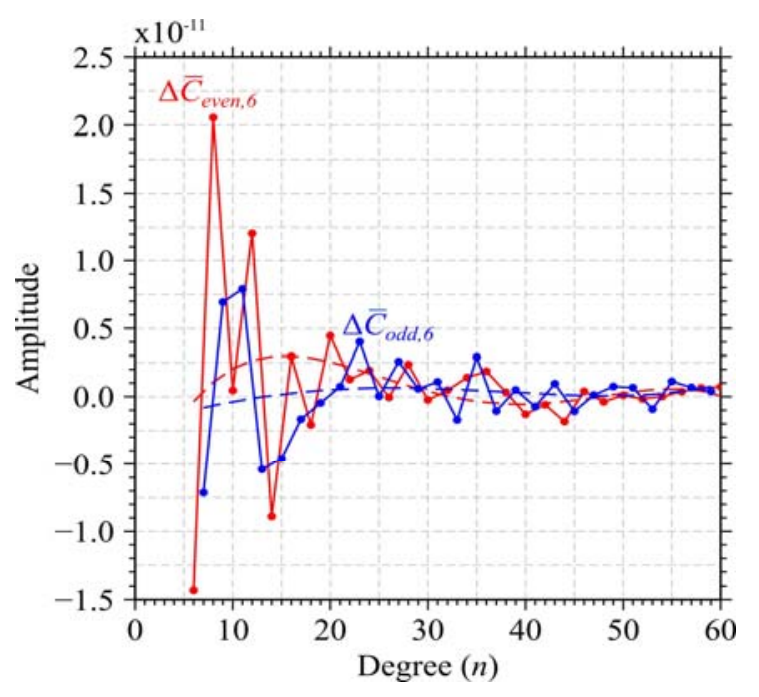

Bol. Ciênc. Geod., sec. Artigos, Curitiba, v. 18, no 4, p.549-563, out-dez, 2012. 
Note: The coefficients was plotted separately for coefficients with degree even (red solid curve) and degree odd (blue solid curve). The P4M6 filter for the degree even (red dashed curve) and odd (blue dashed curve) and order 6.

After P4M6 filtering, a Gaussian low-pass filter was applied to further suppress the 72 remaining short-wavelength errors. Given the averaging or smoothing radius $r$, the Gaussian smoothing operator $W$ for a degree $n$ is defined by a recursive relation (WAHR et al., 1998):

$$
W_{0}=\frac{1}{2 \pi}, \quad W_{1}=\frac{1}{2 \pi}\left(\frac{1+e^{-2 b}}{1-e^{-2 b}}-\frac{1}{b}\right), \quad W_{n+1}=-\frac{2 n+1}{b} W_{n}+W_{n-1},
$$

where the parameter $b$, given the half-height length, is:

$$
b=\frac{\ln (2)}{1-\cos \left(\frac{r}{R}\right)} \text {. }
$$

Following Ramillien et al. (2005) the choice of the $r$ is a good compromise between spatial resolution and effect of noise. The selection of a smoothing radius of $300 \mathrm{~km}$ is also a compromise in that it removes the striping effects, but still allows to study sub-basin changes.

\subsection{The terrestrial hydrological water balance}

It is well known that the water budget methods are based on the principle of conservation of mass applied to some part of the hydrologic cycle, cf. Brutsaert (2008). Over a land-surface of area $\Omega$, the mean evaporation rate, $E$, can be expressed in terms of the water balance equation as follows (BRUTSAERT 2008, p. 142):

$$
E(t)=P(t)-Q(t)-\frac{d W(t)}{d t},
$$

where $P$ is the areal mean rate of precipitation; $Q$ is the mean net surface runoff rate per unit area from the basin (assumed to include both the surface and the groundwater runoff of the area); and $W$ is the water volume stored per unit area.

If we integrate the both sides of the (6) as:

$$
W(t)=\int_{t_{1}}^{t}[P(t)-Q(t)-E(t)] d t,
$$

we can compare the GRACE-derived equivalent water thickness with the right hand side of (7) where $t_{1}$ and $t$ are the first day and the last days of the month. However, Ogawa et al. (2011) reported that a linear trend in $P(t), Q(t)$, and $E(t)$ implies, 
after the integration as in (7), in a quadratic term in $W(t)$. Crowley et al. (2007) after separated the quantities in the (7) into constant, linear, quadratic, and seasonal terms found a good agreement between water volume stored anomalies from GRACE and the integrated precipitation anomalies within the Amazon Basin, South American and Congo Basin, Africa. We apply the same approach to detect the mass changes over Volta Basin at annual and inter-annual time scales.

\subsection{Precipitation data}

In this paper we used the global monthly accumulated rain grids supplied by the Tropical Rainfall Measuring Mission (TRMM) as Level-3 V7 products, more specifically the TRMM 3B43. TRMM is a joint satellite mission of Goddard Space Flight Centre (GSFC), from National Aeronautics and Space Administration (NASA), and the Japan Aerospace Exploration Agency (JAXA). Since the end of 1997, the TRMM provides monthly rainfall rates for the tropical and subtropical regions. Owing to the availability of the GRACE products (CFZ-RL05) at the time of the study, the used time period is limited to January 2005 to December 2010 (total 72 grids) with $0.25^{\circ} \times 0.25^{\circ}$ of spatial resolution available at: http:/gdata1.sci.gsfc.nasa.gov/daac-bin/G3/gui.cgi?instance_id=TRMM_L3_comp.

The precipitation data was also filtered, as EWT derived from $\overline{\text { GRACE}}$, by applying a Gaussian filter (smoothing $300 \mathrm{~km}$ ). It was necessary for a direct comparison with GRACE water storage changes. Following Wahr et al. (1998), in spatial representation the Gaussian smooth is defined by:

$$
W(\psi)=\frac{b}{2 \pi} \frac{e^{-b(1-\cos \psi)}}{1-e^{-2 b}},
$$

where $\psi$ is the spherical distance between the points (the center of the study area and each grid point). We decided use $300 \mathrm{~km}$ for the smoothing radius because the study area is relative small in longitude $\left(10^{\circ}\right)$.

\section{RESULTS AND DISCUSSIONS}

The GRACE-derived EWT were compared with rainfall data at the Volta River basin in West African to assess mass changes expressed as water storage changes and detect its mechanisms. To discuss seasonal or inter-annual changes, the time-series of EWT and precipitation at a given grid point was analyzed using the following expression:

$$
y(t)=a_{0}+a_{1}\left(t-t_{0}\right)+a_{2}\left(t-t_{0}\right)^{2}+\sum_{k=1}^{2}\left[b_{k} \cos (k \omega t)+c_{k} \sin (k \omega t)\right],
$$

where $t$ is a given time point expressed by years from a reference epoch; $y(t)$ is the original input series; $\omega$ is the frequency ( $\omega=2 \pi / T$, where $T$ is the period, one 
year in our analyses); $k$ represents the rank of the harmonics ( $k=1$ corresponds to the fundamental component). The magnitude and phase of the selected harmonic component are calculated by $A_{k}=\sqrt{b_{k}^{2}+c_{k}^{2}}$ and $\Phi_{k}=\arctan \left(c_{k} / b_{k}\right)$, respectively. The coefficient $a_{1}$ represents an instantaneous trend at the epoch $t_{0}$, here $t_{0}=2007.5$, i.e., the mid-point of our time span. The terms $a_{0}$ and $a_{2}$ are the offset depending on the start point of the time series and the acceleration/deceleration (OGAWA et al., 2011), respectively.

The Figure 4 shows the inter-annual changes in EWT and rainfall in mm per year $(\mathrm{mm} / \mathrm{yr})$. The largest EWT rates were found at Volta Lake. The trend indicates a mass increase over Volta River basin (up to $30 \mathrm{~mm} / \mathrm{yr}$ in the Volta Lake). In addition, the rates of rainfall were low $3 \mathrm{~mm} / \mathrm{yr}$ at Lake Volta. Therefore, the positive rate of GRACE-derived EWT is most likely caused by the water impoundment at the Volta Lake. For the EWT the trend reached the maximal values in the south, while in the north values were relative small. Furthermore, it seems the northern parts experiences more drier periods relative to the southern parts. It makes sense if we take into account that the annual rainfall varies greatly across the basin, from $1,500 \mathrm{~mm}$ in the south to $400 \mathrm{~mm}$ in the north.

Figure 4 - Inter-annual trends in EWT (left) and rainfall (right) in $\mathrm{mm} / \mathrm{yr}$ for the period from 2005 to 2010 and the reference epoch is 2007.5 .

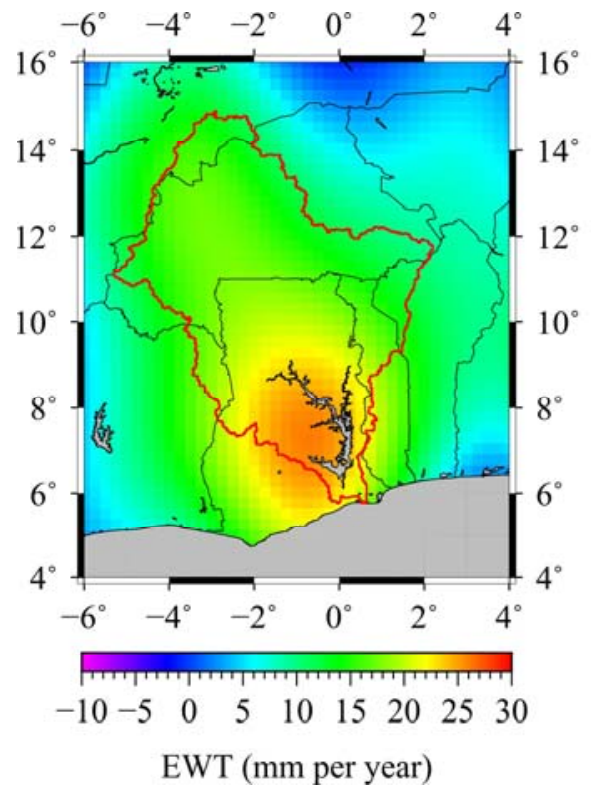

EWT (mm per year)

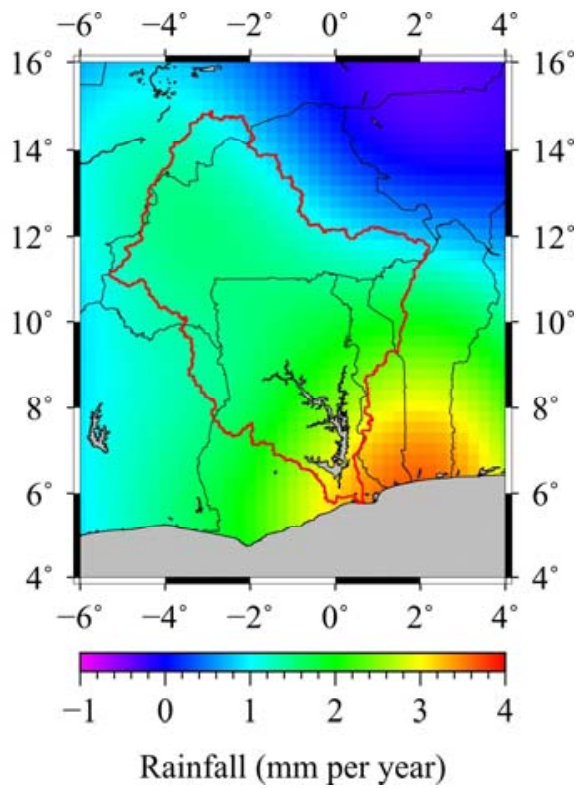

Rainfall (mm per year) 
Figure 5 illustrates the amplitude $A_{1}$ (the annual signal) for EWT (left) and the rainfall (right) as well. The amplitudes of the annual signal of the EWT and the rainfall show quite similarities. The spatial distribution of the amplitude is dominated in the tropical transition zone by larges amplitudes in the EWT. This tropical transition zone is characterized with two rainfall seasons close to each other. Furthermore, for the entire study area, the correlation coefficient between the EWT annual amplitudes and the rainfall annual amplitudes was about the 0.63 . This means that, at the annual scale, the precipitation can explain about the $63 \%$ of the EWT variations, i.e., the EWT are not only caused by the occurrence of rainfall. However, if we look at the relation (7) we can see that only a small portion of precipitation accumulates in the region. Part of the water from rainfall evaporates and runs-off into the rivers and lakes. There must be some other processes involved, such as, mass transport from one region to another, which cause mass changes without rainfall.

Figure 5 - The amplitude of the annual signal in $\mathrm{mm}$ are shown in panels where the left one for the EWT and in the right one for the rainfall.
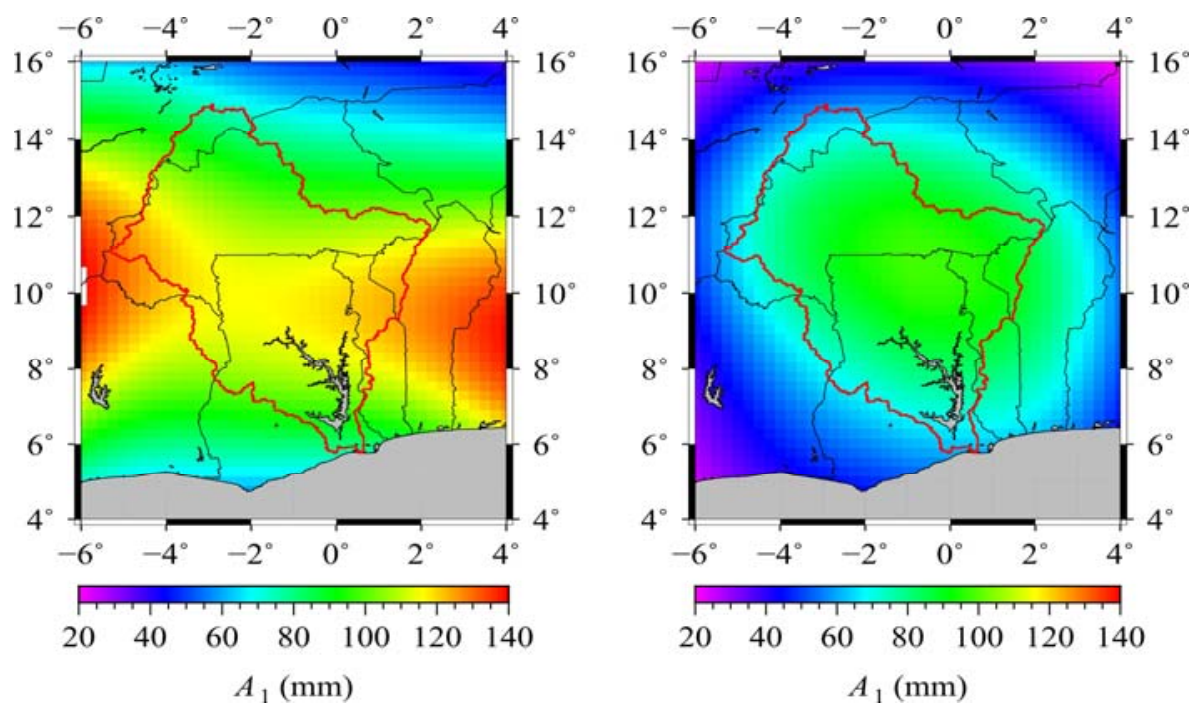

To determine the relationship between both data sets, linear correlation coefficients were assessed at the seasonal scale. This was obtained by computing the correlation coefficient between the time series of EWT and rainfall for every grid point. We removed the constant $a_{0}$, linear $a_{1}$ and quadratic $a_{2}$ terms, $c f$. the expression (9), in both time series (EWT and rainfall) for each grid point. The results for the correlation coefficients are illustrated in Figure 6 (left). It can be 
recognized that for the tropical climate zone very similar correlation coefficients (around 0.3) are present. The mean value accounts for approximately 0.2, which indicates a low correlation. A possible explanation for the low correlation coefficient is that the both signal are not in phase indicating an offset in time or the influence of one variable may be spread over several observations of the other variable.

Rieser et al. (2010) reported that precipitation generally precedes EWT, and it takes some time until the accumulated water from precipitation is monitored as gravity change by GRACE. However, instead of using cross correlation function to determine the phase difference between the annual signals, we can use the differencing the phases obtained for each data set separately (ibid). In Figure 6 (right), the phase differences between EWT and rainfall $\left(\Phi_{\mathrm{EWT}}-\Phi_{\text {rainfall }}\right)$ are illustrated for the annual signals for each grid point. In the study area, rainfall appears approximately 1 to 4 months (from the south to north) before mass changes be detected by GRACE. This means that a rainfall event has occurred and then it takes between 1 to 4 months for the water mass be detected by GRACE mission.

Figure 6 - Correlation coefficients (left) of EWT and rainfall, phase differences (right) between EWT changes and rainfall.

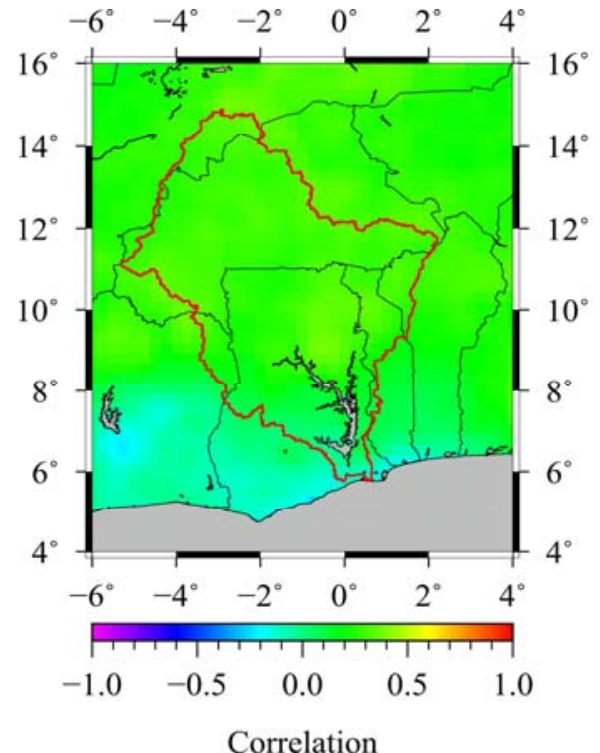

Correlation

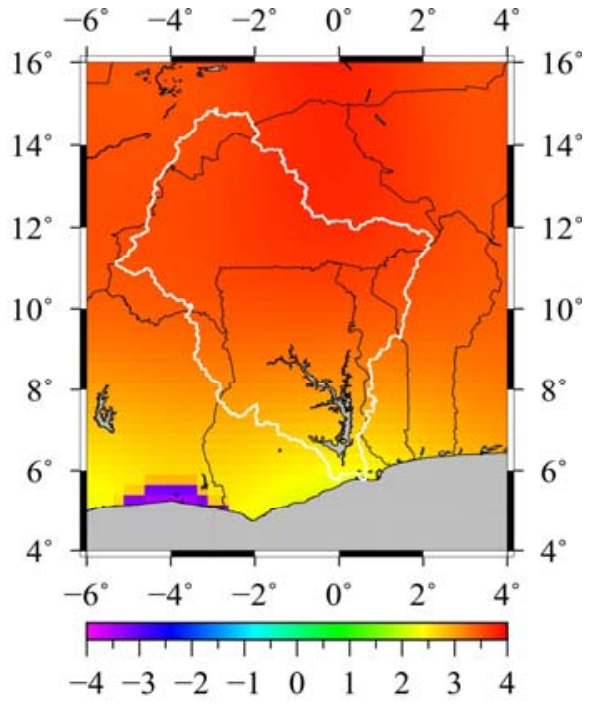

$\Delta \Phi$ (months)

Note: Positive values for phase differences (right) mean that the rainfall time series precede EWT time series and vice versa for negative phase differences. 


\section{CONCLUSION}

We have assessed the water storage changes over the Volta River basin, West African to detected mass changes and its mechanisms. To achieve this goal, we have used the GRACE monthly gravity field solutions in the form of Stokes's coefficients and compared with precipitation data from TRMM grids. The comparison between terrestrial water storage changes and precipitation allowed the identification of the processes that need to be taken into account to understand mass changes over the study area. We found that the EWT in the Volta River basin increased over the period under consideration (January 2005 to December 2010 at a specific epoch 2007.5) from $20 \mathrm{~mm} / \mathrm{yr}$ in the south part of the basin to $10 \mathrm{~mm} / \mathrm{yr}$ in the north part. The analysis of seasonal variations revealed that mass changes are preceded by rainfall by about one month in the south of the basin while in the north about the four months. Future work should benefit greatly by using in-situ hydrology observations (e.g., river level, river flow, soil moisture, etc.) to detect mass transport over Volta River basin.

\section{ACKNOWLEDGEMENTS:}

Vagner G. Ferreira acknowledges the support through a grant 2012B01314 from the Hohai University. Zheng Gong acknowledges the State Key Development Program of Basic Research of China (2010CB429001), the Special Fund of State Key Laboratory of Hydrology-Water Resources and Hydraulic Engineering (2009586812), and the National Natural Science Foundation of China (Grant No. 51009062 and Grant No. 51179067). We thank two anonymous reviewers for constructive comments.

\section{REFERENCES}

AWANGE, J. L.; SHARIFI, M. A.; BAUR, O. et al. GRACE hydrological monitoring of Australia: Current limitations and future prospects. Journal of Spatial Science, v. 54, n. 1, p. 23-36, 1 Jun 2009.

BETTADPUR, S.; CSR Level-2 Team, Insights into the Earth System mass variability from CSR-RL05 GRACE gravity fields, Geophysical Research Abstracts, Vol. 14, EGU2012-6409, EGU General Assembly 2012. 2012.

BRUTSAERT, W. Hydrology: an introduction. 3rd ed. Cambridge: Cambridge University Press. 2008.

CHEN, J. L.; WILSON, C. R.; TAPLEY, B. D. et al. Recent La Plata basin drought conditions observed by satellite gravimetry. Journal of Geophysical Research, v. 115, n. D22, 18 Nov 2010.

CHEN, J. L.; WILSON, C. R.; TAPLEY, B. D.; GRAND, S. GRACE detects coseismic and postseismic deformation from the Sumatra-Andaman earthquake. Geophysical Research Letters, v. 34, n. 13, p. 1-5, 4 Jul 2007.

CHENG, M.; TAPLEY, B. D. Variations in the Earth's oblateness during the past 28 years. Journal of Geophysical Research, v. 109, n. B9, p. B09402, 16 Sep 2004. 
CHENG, M.; RIES, J. Monthly estimates of C20 from 5 SLR satellites based on GRACE RL05 models. GRACE Technical Note 07, 2012. Available at http://isdc.gfz-potsdam.de/index.php?name=News\&file=article\&sid=118 (last accessed 2012 July 28).

CROWley, J. W.; MitroviCA, J. X.; BAIley, R. C.; TAMiSIEA, M. E.; DAVIS, J. L. Land water storage within the Congo Basin inferred from GRACE satellite gravity data. Geophysical Research Letters, v. 33, n. 19, p. 25, 3 Oct 2006.

CROWley, J. W.; MitroviCA, J. X.; BAIley, R. C.; TAMiSIEA, M. E.; DAVIS, J. L. Annual variations in water storage and precipitation in the Amazon Basin. Journal of Geodesy, v. 82, n. 1, p. 9-13, 26 Apr 2007.

DAHLE, C.; FLECHTNER, F.; GRUBER, C.; KÖNIG, D.; KÖNIG, R.; MICHALAK, G.; NEUMAYER, K.-H. GFZ GRACE Level-2 Processing Standards Document for Level-2 Product Release 0005, Scientific Technical Report, Potsdam, 20 p., 2012.

DEUS, D.; GLOAGUEN, R.; KRAUSE, P. Water balance modelling in a semi-arid environment with limited in-situ data: remote sensing coupled with satellite gravimetry, Lake Manyara, East African Rift, Tanzania. Hydrology and Earth System Sciences Discussions, v. 8, n. 5, p. 8737-8792, 26 Sep 2011.

DUAN, X. J.; GUO, J. Y.; SHUM, C. K.; WAL, W. On the postprocessing removal of correlated errors in GRACE temporal gravity field solutions. Journal of Geodesy, v. 83, n. 11, p. 1095-1106, 17 Jun 2009.

GRIPPA, M.; KERGOAT, L.; FRAPPART, F. et al. Land water storage variability over West Africa estimated by Gravity Recovery and Climate Experiment (GRACE) and land surface models. Water Resources Research, v. 47, n. 5, p. 1-18, 28 May 2011.

HINDERER, J.; PFEFFER, J.; BOUCHER, M. et al. Land Water Storage Changes from Ground and Space Geodesy: First Results from the GHYRAF (Gravity and Hydrology in Africa) Experiment. Pure and Applied Geophysics, v. 169, n.8, p. 1391-1410, 14 Oct 2011.

KLEES, R.; LIU, X.; WITTWER, T. et al. A Comparison of Global and Regional GRACE Models for Land Hydrology. Surveys in Geophysics, v. 29, n. 4-5, p. 335-359, 5 Dec 2008.

KUSCHE, J. Approximate decorrelation and non-isotropic smoothing of timevariable GRACE-type gravity field models. Journal of Geodesy, v. 81, n. 11, p. 733-749, 27 Feb 2007.

LENK, O. Satellite based estimates of terrestrial water storage variations in Turkey. Journal of Geodynamics. Available at http://www.sciencedirect.com/ science/article/pii/S0264370712000713 (last accessed 2012 April 25).

MILZOW, C.; KROGH, P. E.; BAUER-GOTTWEIN, P. Combining satellite radar altimetry, SAR surface soil moisture and GRACE total storage changes for hydrological model calibration in a large poorly gauged catchment. Hydrology and Earth System Sciences, v. 15, n. 6, p. 1729-1743, 6 Jun 2011. 
OGAWA, R.; CHAO, B. F.; HEKI, K. Acceleration signal in GRACE time-variable gravity in relation to interannual hydrological changes. Geophysical Journal International, v. 184, n. 2, p. 673-679, 22 Feb 2011.

RAMILlIEN, G.; FAMIGLIETTI, J. S.; WAHR, J. Detection of Continental Hydrology and Glaciology Signals from GRACE: A Review. Surveys in Geophysics, v. 29, n. 4-5, p. 361-374, 7 Nov 2008a.

RAMILLIEN, G.; BOUHOURS, S.; LOMBARD, A. et al. Land water storage contribution to sea level from GRACE geoid data over 2003-2006. Global and Planetary Change, v. 60, n. 3-4, p. 381-392, Feb 2008b.

RAMILliEN, G.; FRAPPART, F.; CAZENAVE, A; GUNTNER, A. Time variations of land water storage from an inversion of 2 years of GRACE geoids. Earth and Planetary Science Letters, v. 235, n. 1-2, p. 283-301, 30 Jun 2005.

RIESER, D.; KUHN, M.; PAIL, R.; ANJASMARA, I. M.; AWANGE, J. Relation between GRACE-derived surface mass variations and precipitation over Australia. Australian Journal of Earth Sciences, v. 57, n. 7, p. 887-900, out 2010.

SCHRAMA, E. J. O.; VISSER, P. N. A. M. Accuracy assessment of the monthly GRACE geoids based upon a simulation. Journal of Geodesy, v. 81, n. 1, p. 67-80, 29 Aug 2006.

SWENSON, S.; WAHR, JOHN. Post-processing removal of correlated errors in GRACE data. Geophysical Research Letters, v. 33, n. 8, p. 1-4, 2006.

SYED, T. H.; FAMIGLIETTI, JAMES S.; RODELL, M.; CHEN, J.; WILSON, CLARK R. Analysis of terrestrial water storage changes from GRACE and GLDAS. Water Resources Research, v. 44, n. 2, 22 Feb 2008.

TANGDAMRONGSUB, N.; HWANG, C.; KAO, Y.-C. Water storage loss in central and south Asia from GRACE satellite gravity: correlations with climate data. Natural Hazards, v. 59, n. 2, p. 749-769, 30 mar 2011.

WAHR, J.; MOLENAAR, M.; BRYAN, F. Time variability of the Earth's gravity field: Hydrological and oceanic effects and their possible detection using GRACE. Journal of Geophysical Research, v. 103, n. B12, p. 30205-30229, 1998.

XIE, H.; LONGUEVERGNE, L.; RINGLER, C.; SCANLON, B. Calibration and evaluation of a semi-distributed watershed model of sub-Saharan Africa using GRACE data. Hydrology and Earth System Sciences Discussions, v. 9, n. 2, p. 2071-2120, 17 Feb 2012.

(Recebido em agosto de 2012. Aceito em outubro de 2012.) 